\title{
EL ESTADO DE DERECHO Y LA SEGURIDAD JURÍDICA LO QUE DEBE RESGUARDAR EL DEDECON
}

THE RULE OF LAW AND LEGAL SECURITY WHAT MUST BE SAFEGUARD BY THE DEDECON

\begin{tabular}{|c|c|}
\hline \multicolumn{2}{|c|}{ ARTÍCULO INÉDITO DE INVESTIGACIÓN } \\
\hline CÓMO CITAR ESTE ARTÍCULO (CHICAGO) & 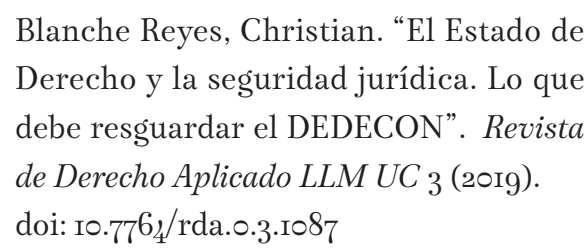 \\
\hline REVISTA DE DERECHO APLICADO LLM UC & $\begin{array}{l}\text { Número } 3 \\
\text { Julio } 2019 \\
\text { ISSN: } 2452-4344\end{array}$ \\
\hline & $\begin{array}{l}\text { Recepción: } 5 \text { de abril, } 2019 \\
\text { Aceptación: I de julio, } 2019\end{array}$ \\
\hline
\end{tabular}




\section{Resumen}

La complejidad del sistema tributario, las constantes modificaciones legislativas, la falta de control de las facultades discrecionales de la administración tributaria, el alto interés moratorio que genera una liquidación de impuestos y, en general, la creciente necesidad de recaudar impuestos, generan una inseguridad jurídica en materia tributaria, que ha afectado gravemente los derechos de los contribuyentes. Dentro de otras medidas, para reforzar el Estado de Derecho en materia tributaria, es indispensable la creación de la Defensoría del Contribuyente (DEDECON), como lo ha planteado el Proyecto de Ley sobre Modernización Tributaria del Ejecutivo.

Palabras clave: facultades discrecionales, falta de control, inseguridad jurídica, derechos del contribuyente, defensoría del contribuyente

\section{Abstract}

The complexity of the tax system, the constant legislative changes, the lack of control of the discretionary powers by the tax administration, the high interest rate that generates a tax reassessment, and in general, the growing need to collect taxes, generate a legal uncertainty in tax matters, which seriously affects the taxpayers' rights. Within other measures, to strengthen the rule of law in tax matters, it is essential to create the Taxpayer Advocacy Service (Defensoría del Contribuyente, or, DEDECON), as proposed by the Tax Modernization Project of the Executive.

Keywords: discretionary powers, lack of control, legal uncertainty, taxpayer rights, Taxpayer Advocacy Service 


\section{Christian Blanche Reyes}

Pontificia Universidad Católica de Chile

Magíster en Derecho, LLM UC

Santiago, Chile

cblanchr@uc.cl
Pontificia Universidad Católica de Chile

Master in Law, LLM UC

Santiago, Chile

cblanchr@uc.cl
Abogado de la Universidad de Chile, Postgrado en Gestión de Empresas de la Pontificia Universidad Católica de Chile. Fundador y Socio Principal de Tax Advisors, firma especializada en materias tributarias. Profesor del Magíster en Derecho, LLM UC (PUC). Destacado en Latinoamérica por Chambers \& Partners como especialista tributario. Ha sido director del Instituto Chileno de Derecho Tributario (ICHDT) y de la International Fiscal Association (IFA Chile AG). También ha sido Miembro Comisión Tributaria Colegio de Abogados AG y actualmente es Presidente de la Comisión Tributaria de la Confederación de la Producción y del Comercio (CPC).

Lawyer from the Universidad de Chile, Postgraduate in Business Management from the Pontificia Universidad Católica de Chile. Founder and Senior Partner of Tax Advisors, a firm specialized in tax matters. Professor of the Master in Law, LLM UC (PUC). Featured in Latin America by Chambers $\&$ Partners as a tax specialist. He has been director of the Instituto Chileno de Derecho Tributario (Chilean Institute of Tax Law) and the International Fiscal Association (IFA Chile AG). He has also been a Member of the Tax Commission of the Chilean Bar Association AG and is currently President of the Tax Commission of the Confederación de la Producción y del Comercio (Confederation of Production and Commerce). 


\section{Principios}

\section{I.I El Estado de Derecho}

El Estado de Derecho está compuesto por dos elementos básicos, por un lado el Estado, forma de organización política constituida por instituciones estables que ejercen soberanía, a través de las cuales detentan el monopolio del uso de la fuerza pública dentro de sus límites territoriales; y el Derecho, que es el conjunto de normas que rigen el funcionamiento de la sociedad, y que en caso de no cumplirse se pueden exigir coercitivamente. En consecuencia, cuando existe un Estado de Derecho, el ejercicio del poder por parte del Estado se encuentra limitado por el ordenamiento jurídico. ${ }^{1}$

Surge como oposición al Estado absolutista, donde el Rey se encontraba por encima de todas las demás personas y podía ordenar y mandar sin ningún otro poder que le hiciera contrapeso. En un Estado de Derecho, el poder surge del pueblo, quien elige a sus representantes para el gobierno y, por tanto, se vincula con la democracia. Con el desarrollo del Estado de Derecho, aparece la división clásica de los poderes, el Poder Ejecutivo, el Poder Legislativo y el Poder Judicial, tres potestades que, en el Estado absolutista, se reunían en la figura del Rey. Con el Estado de Derecho, los Tribunales de Justicia se vuelven autónomos respecto al soberano y aparece el Congreso o Parlamento para contrarrestar al Poder del Ejecutivo.

En todo Estado existe un ordenamiento jurídico, lo que no necesariamente significa que quienes ejercen el poder se encuentren limitados por él, ya que para que exista un Estado de Derecho es necesario que toda la sociedad política se encuentre sometida a las mismas normas aplicables a las personas comunes y donde dichas normas aseguren que todas las personas tendrán acceso a la justicia. En consecuencia, el Estado de Derecho supone: a) que la Ley es la norma fundamental, donde todos los administrados, y especialmente quienes los gobiernan, deben someterse a las leyes y ser juzgados en igualdad de condiciones que las demás personas y no se harán excepciones a ningún individuo, por alto que sea el cargo que posea; $b$ ) que están garantizados los derechos de las personas, siendo responsabilidad del Estado que la Ley se cumpla y que en ella se consagre la libertad de todos los que viven bajo su potestad; y c) que las facultades administrativas se encuentran limitadas por la Ley, lo que implica que los funcionarios del Estado, que forman parte del gobierno central, regional y comunal, se encuentran subordinados al ordenamiento jurídico. ${ }^{2}$ En materia tributaria, la plena vigencia del Estado de Derecho adquiere una dimensión

1 Como dijo el historiador y político inglés Lord Acton (I834-I9०2), "Power tends to corrupt, and absolute power corrupts absolutely", esto es, el poder tiende a corromper y el poder absoluto corrompe absolutamente.

2 El Estado de Derecho se ha visto vulnerado en numerosas ocasiones en materia tributaria y, recientemente, en el ejercicio de la acción penal, en el caso del financiamiento de la política. 
propia, cuando los recursos fiscales son escasos y su obtención constituye un objetivo estratégico de la política económica para mantener la regla fiscal, pese al constante aumento del gasto público y a la poca eficiencia en el manejo de los recursos. Lo anterior ha hecho que en nuestro país, en las últimas décadas, las normas tributarias presten más atención a los mecanismos que recaudan y que impiden la elusión y la evasión de los impuestos, en desmedro de los derechos de los contribuyentes. Hoy el gasto público se encuentra con nuevas demandas para el financiamiento de los gobiernos regionales, sin dejar de aumentar los gastos en salud y otras prestaciones asistenciales. Los contribuyentes requieren de claridad y transparencia, no sólo en los impuestos que deben pagar, sino también en el buen uso de los recursos por parte del Estado, que es lo que finalmente legitima el sistema tributario. ${ }^{3}$ En este último punto nos parece un acierto la creación del Consejo Fiscal Autónomo (Ley N ${ }^{\circ}$ 21.148), para contribuir con el manejo responsable de la política fiscal del Gobierno Central. Su consagración legal ayuda a la seguridad jurídica en materia tributaria.

En este sentido, la necesidad de aumentar la recaudación ha llevado muchas veces a que la autoridad administrativa haya abusado en el ejercicio de sus facultades al interpretar administrativamente la legislación tributaria; los tribunales de justicia hayan recurrido al espíritu de la ley desconociendo su tenor literal para combatir las denominadas planificaciones agresivas $^{45}$; y el Congreso haya aprobado cambios legislativos sin el debido debate y apoyo técnico. Todo lo anterior ha generado falta de claridad para poder interpretar el alcance y sentido de la obligación tributaria.

Sin embargo, no ha existido por parte del Estado la misma preocupación por el control del gasto público. No sólo se debe exigir a los particulares contribuir con el gastos social, sino también y con la misma rigurosidad a la administración del Estado ser eficiente en el uso de estos recursos. A modo de ejemplo, Jeannette Von Wolfersdorff, directora de Observatorio Fiscal, ha señalado que «probablemente ningún parlamentario que apruebe la Ley de Presupuestos tiene claro el destino, los objetivos estratégicos y los resultados esperados del gasto que aprueba» ${ }^{6}$. Por otra parte, cuando los ingresos no han cumplido el

3 Axel Kaiser, "Estado, impuestos y explotación”, Economía y Negocios, $2_{4}$ de abril de 20I8. En su columna, el Director Ejecutivo de la Fundación para el Progreso ha señalado que: "Ese grupo de personas que llamamos Estado tiene la obligación de velar por que los impuestos sean lo más bajo posible, pues el dinero que sustraen no es de ellos ni de aquellos que pretenden beneficiar, sino de los pagadores de impuestos que lo han generado con su trabajo”.

4 Sentencia de la Corte Suprema Rechazando Casación, Rol 27.783 del año 20I4, de fecha 23 de diciembre del año 2015 .

$5 \quad$ Sentencia de la Corte Suprema de Reemplazo, Rol $32 . \mathrm{II}_{4}$ del año $20 \mathrm{I}_{4}$, de fecha $\mathrm{I}_{4}$ de septiembre del año 20I5.

6 Jeannette Von Wolfersdorff, “No hace bien a la institucionalidad un debate tan duro", Diario Financiero, II de mayo de 2018. 
presupuesto, el Fisco se ha tenido que endeudar, generando un desequilibrio en las cuentas fiscales. Como señala el profesor Erik Haindl, para tener un déficit fiscal sostenible, lo clave es que la deuda pública no aumente más rápido que el PIB .

Como consecuencia de lo anterior, la recaudación se ha transformado en un objetivo en sí mismo y se han dejado de lado los derechos de los contribuyentes. Lo anterior ha afectado en mayor medida a quienes no cuentan con los recursos para contratar a un asesor y poder defenderse ante una vulneración de sus derechos. En efecto, hoy las PYMES no cuentan con el apoyo del Estado, cuando se trata de situaciones vinculadas con el cumplimiento de la obligación tributaria. Agrava la situación la tasa de interés moratorio que cobra el Fisco, en caso de existir una deuda tributaria, y que asciende a un $18 \%$ de interés anual. Esta tasa es excesiva e injusta para los contribuyentes. ${ }^{8}$ En una encuesta efectuada a nivel nacional, por el Instituto de Libertad y Desarrollo, realizada en noviembre de 2018 a 300 empresas PYMES, acerca de su opinión del Proyecto de Ley sobre Modernización Tributaria (PLMT), la propuesta mejor valorada fue la creación del Defensor del Contribuyente, obteniendo una nota promedio de $6,1^{9}$

Por otra parte, es necesario destacar que en materia de impuestos, el resguardo de los derechos de las personas es más necesario, porque se produce la "triple identidad del Estado", éste crea la ley tributaria, luego la aplica y en caso de conflicto, resuelve las controversias del Fisco con los particulares, concentrándose en una sola mano la potestad tributaria. Por esta razón, debe existir el debido control de esta potestad, para lo cual es imprescindible reforzar el estatuto de los derechos de los contribuyentes y crear la institución del Defensor de los Contribuyentes. Los contribuyentes son quienes finalmente permiten que el Estado subsista y pueda cumplir sus obligaciones. Hay que buscar un justo equilibrio entre la necesidad de recaudar para satisfacer las necesidades sociales y los derechos constitucionales de aquellos cuyo patrimonio debe soportar esta pesada carga.

\section{I.I La seguridad jurídica}

La seguridad jurídica es un principio universalmente reconocido, que se basa en la certeza del derecho, tanto en el ámbito de su publicidad como en su aplicación, y que significa la

7 Erik Haindl, "El fracaso de la Regla Fiscal". Diario Financiero, (o8 de mayo de 20I8), https://www.df.cl/noticias/opinion/columnistas/erik-haindl/el-fracaso-de-la-reglafiscal/2018-05-07/19०313.html.

8 El Tribunal Constitucional en Sentencia de 25 de octubre de 20I8, Rol 3·440-I7, acogió un requerimiento de inaplicabilidad que impugna el artículo 53 inciso $3^{\circ}$ del Código Tributario, que regula el interés moratorio.

9 Libertad y Desarrollo, "Propuesta de Modernización Tributaria, efecto en las Pymes" (noviembre de 20I8),, https://yd.org/wp-content/uploads/20I8/r2/encuesta-modernizacion-tributaria-pymes.pdf . 
seguridad de que se conoce, o puede conocerse, lo que está prohibido, ordenado o permitido por la autoridad. Asimismo, la seguridad jurídica supone tener claridad, certeza y estabilidad en las decisiones que se adoptan, como en la posibilidad de aclarar las interpretaciones administrativas y los asuntos disputados con un costo y tiempos razonables. ${ }^{10}$

Tratándose de seguridad jurídica en materia tributaria, cabe destacar que en septiembre del año 2016, los líderes del G20, en la reunión que tuvieron en China (Hangzhou), concluyeron que era necesario abordar los crecientes problemas en esta materia (tax certainty). Si bien reconocían haber realizado significativos avances en la lucha contra la evasión fiscal, la planificación fiscal agresiva y la transparencia tributaria, en el marco del proyecto BEPS promovido por la OCDE, concluyeron que era prioritario, tanto para los gobiernos como para las empresas, contar con una mayor seguridad jurídica en materia tributaria, para apoyar el comercio, la inversión y el crecimiento económico.

A finales de 2016, la OCDE realizó una encuesta en la que participaron expertos tributarios pertenecientes a 724 empresas localizadas en 62 diferentes países. Una encuesta similar fue realizada por la OCDE en enero de 2017 a representantes de 25 administraciones tributarias. La investigación concluyó que, el sistema tributario constituye un factor clave a la hora de adoptar decisiones de inversión y localización, y que las principales causas de la inseguridad jurídica provienen de la burocracia para cumplir las obligaciones tributarias, los distintos criterios seguidos por las administraciones al aplicar los estándares fiscales internacionales, la compleja y poco clara legislación, los frecuentes cambios legislativos, la retroactividad de las normas, y los prolongados procesos judiciales. ${ }^{11}$

Siguiendo la tendencia internacional, la seguridad jurídica es uno de los pilares del PLMT que se está debatiendo en el Congreso. ${ }^{12}$ En efecto, el proyecto fortalece el principio de legalidad tributaria, establece controles a las facultades discrecionales que posee el Servicio de Impuestos Internos, perfecciona el estatuto de los derechos del contribuyente y crea la tan esperada Defensoría del Contribuyente (DEDECON).

Sin embargo, el debate del PLMT a nivel político, se ha centrado en la recaudación y en evitar restringir las facultades de fiscalización con que cuenta la autoridad fiscal para cumplir este objetivo, y se han olvidado de destacar la importancia de reforzar los derechos

10 Sentencia de la Corte de Apelaciones de Santiago, Rol Ingreso Corte Civil 6785 del año 20r7, de fecha 26 de octubre del año 2017 , considerando noveno.

11 AEDAF, "Inseguridad Jurídica en España: situación actual y propuesta para el futuro." Paper ${ }_{3}$, diciembre de 20I8. http://mediasviewer.wkcols.com/pdfView.ashx?url_data_id=8875526\&repositoryType $=$ es\&action $=$ GET.

12 Mensaje $\mathrm{N}^{\circ}$ I07-366/ Santiago, 23 de agosto de 20I8, con el que el Presidente inicia el Proyecto de Ley que Moderniza la Legislación Tributaria. 
de las personas, naturales y jurídicas, que con los impuestos que pagan logran financiar todo el aparato público. Hoy se gastan importantes recursos para financiar organismos estatales de todo tipo (como el Servicio Nacional del Consumidor y muchos otros), pero inexplicablemente no existe ninguna institución fiscal que resguarde los derechos de los contribuyentes.

Si bien es indiscutible que uno de los deberes básicos de toda persona es contribuir con sus impuestos al gasto público, que por lo demás es un principio ético de solidaridad social, también lo es que ello debe darse necesariamente en un marco de seguridad jurídica, con pleno respeto a los derechos de los contribuyentes que, conforme con los acuerdos internacionales suscritos por Chile, como el Pacto de San José de Costa Rica, son considerados parte de los derechos humanos.

Claramente, nuestro país requiere de una mayor seguridad jurídica, tanto para la elaboración y aplicación de la legislación tributaria, como para la resolución de los conflictos que generan. El PLMT se hace cargo de esto, entre otras cosas, creando la Defensoría del Contribuyente, en su artículo 23.

\section{Antecedentes de la DEDECON}

La Defensoría del Contribuyente se crea en el derecho occidental a partir de la institución del Ombudsman, que nace en Suecia en 1809, para velar por la protección y salvaguarda de los derechos humanos. El Ombudsman es un organismo independiente, con autoridad para dirigir recomendaciones a la Administración a fin de corregir los problemas que vaya detectando, como consecuencia de los reclamos y sugerencias que le hace el pueblo. Como señala la doctora Gabriela Dalla Corte ${ }^{13}$, la institución del Ombudsman se consolida en torno a la posibilidad abierta por el Estado para facilitar el acceso a la sociedad civil a las instituciones públicas y contribuir así a la solución de las demandas ciudadanas, propiciando lo que se viene conociendo como "cultura de la reclamación", en la que el Ombudsman, como colaborador crítico del Estado, podría ayudar a superar las situaciones de indefensión. Esta es la institución más idónea para controlar la burocracia y consolidar el Estado de Derecho. Durante el siglo XX, el Ombudsman Tributario se difundió en Europa, América, África y Asia. ${ }^{14}$

13 Gabriela Dalla Corte, "El "Ombudsman". Expectativas de derechos en el poder con fuerza no vinculante" (Tesis para optar al Título de Doctora en Antropología, de la Universidad de Barcelona, 2000), http://diposit.ub.edu/dspace/bitstream/2445/62405/I/DALLA_CORTE_OMBUDSMAN.pdf.

14 También tienen instituciones similares Colombia, Perú, México, España, Canadá, Italia, Japón, USA, entre otros países. 
El Ejecutivo ha propuesto la creación de la Defensoría de los Derechos de los Contribuyentes (DEDECON), tomando la idea de la Procuraduría de Defensa del Contribuyente (PRODECON) que ha sido tan exitosa en $\mathrm{México}^{15}$. No cabe la menor duda que este es uno de los grandes aciertos del PLMT. El Mensaje del Presidente señala que, a través de esta entidad, se busca fomentar la confianza recíproca entre el contribuyente y la autoridad tributaria, incentivando buenas prácticas de fiscalización y cumplimiento tributario.

Así como la Presidenta Bachelet en su primer gobierno, creó los Tribunales Tributarios y Aduaneros (TTA), el actual gobierno avanza en la consolidación de la justicia en materia tributaria, al otorgarle a la ciudadanía el amparo administrativo necesario, frente a los reclamos que pueda tener en contra del organismo que fiscaliza el cumplimiento de la obligación tributaria, evitando de esta forma que los abusos de autoridad queden impunes.

Si bien la reforma tributaria del segundo gobierno de la Presidenta Bachelet creó la Subdirección de Asistencia al Contribuyente, y facultó al Servicio de Impuestos Internos (SII) para celebrar convenios de colaboración con grupos de contribuyentes y capacitarlos, estas medidas se han hecho insuficientes para sanear el ambiente de desconfianza y las incertidumbres que aún presenta nuestro sistema tributario. Por esta razón, celebramos la proposición de incorporar esta institución a nuestro ordenamiento jurídico. Hoy la relación tributaria a nivel mundial mutó de una relación subordinada a los dictados del Príncipe, a una relación de colaboración y transparencia entre el contribuyente y la autoridad.

Aun cuando, en el derecho comparado, algunos Defensores Tributarios se encuentran organizados dentro de la propia administración, todos ellos reciben las quejas que presentan los ciudadanos en contra de la autoridad fiscal. En el caso de USA, el Abogado del Contribuyente (Taxpayer Advocate) y su Delegado en los distintos Estados, tienen incluso la facultad de suspender los procedimientos tributarios y levantar los embargos. Esto obliga al funcionario responsable a tener interés en resolver rápidamente el asunto planteado. ${ }^{16}$ El Defensor nace como una necesidad de canalizar el desconcierto y dar amparo a la impotencia que produce en el contribuyente, el enfrentarse ante el rechazo de las peticiones

15 La PRODECON nace a la vida jurídica con su Ley Orgánica, el 4 de septiembre del 2006. Sin embargo, sólo el 28 de abril del 2or se designó a la primera Procuradora de la Defensa del Contribuyente, Diana Bernal Ladrón de Guevara. La Defensoría abrió sus puertas al público, el I de septiembre de 20 II.

16 José Andrés Rozas y Eva Andrés Aucejo, "El Defensor del Contribuyente un estudio de Derecho Comparado: ITALIA y EEUU. Estudio y Notas”, Crónica Tributaria II3 (Facultad de Derecho Financiero y Tributario. Universidad de Barcelona, 2004), https://www.economistas.es/contenido/REAF/gestor/o6-cro-6-II3.pdf. 
que presenta, aun cumpliendo con las normas legales vigentes. Por otra parte, la correcta información y aplicación de las normas tributarias es un derecho básico de las personas, ya que ello evita incurrir en infracciones civiles o penales, como acceder a los legítimos mecanismos de ahorro tributario que le otorga la denominada economía de opción.

No puede existir reforma más democrática que ésta, ya que garantiza la asesoría y defensa de las personas de menores recursos económicos y constituye la herramienta necesaria para que los derechos de los contribuyentes no sean letra muerta. La DEDECON permitirá construir un nuevo camino para el diálogo y la defensa de los derechos de los contribuyentes y, asimismo, contribuir al mejor funcionamiento y calidad de los servicios que presta la administración tributaria.

\section{Experiencia en el derecho comparado}

A continuación analizaremos la institución de la Defensa de los Contribuyentes en el derecho comparado, dando cuenta de cómo opera en los Estados Unidos y México.

\section{I Estados Unidos}

Como fue señalado en el punto anterior, en Estados Unidos la defensa de los contribuyentes se encuentra a cargo del Tax Advocate Service (TAS), que actúa en forma independiente respecto del Servicio de Impuestos Internos de Estados Unidos (IRS), y que fue creado a partir de la Declaración de Derechos del Contribuyente 2 (Taxpayer Bill of Rights 2 o TBOR2), con el propósito de ayudar a los contribuyentes individuales y comerciales a solucionar problemas que no han podido ser resueltos a través de los canales normales del IRS; y abordar problemas sistémicos a gran escala que afecten a grupos de contribuyentes. ${ }^{17}$

Actualmente, TAS cuenta con aproximadamente 1.800 empleados, y 1.400 de éstos son defensores de casos, quienes asisten personalmente a resolver los problemas de los contribuyentes con el IRS. En cada Estado existe al menos un defensor local, que funciona bajo la supervisión y dirección del National Taxpayer Advocate o Defensor Nacional del Contribuyente, nombrado por el Secretario del Tesoro, después de consultar con el Comisionado y la Junta de Supervisión, ambos del IRS. ${ }^{18}$

Adicionalmente, TAS es apoyado por dos organismos: (i) el primero, denominado Taxpayer Advocacy Panel (Panel de Defensa del Contribuyente), compuesto por 75 ciudadanos voluntarios de Estados Unidos, Puerto Rico y del distrito de Columbia, que actúan

17 [Taxpayer Advocate Service] (s.f.), https://taxpayeradvocate.irs.gov/about-tas

18 [Olson Named National Taxpayer Advocate]. (I2.0I.200I), https:/www.irs.gov/pub/irs-news/ ir-oI-o6.pdf 
como intermediarios entre el IRS y los contribuyentes, escuchando a estos últimos e identificando problemas y realizando sugerencias para mejorar los servicios de la autoridad fiscal y su eficiencia. Cabe mencionar que este Panel no tiene la autoridad para abordar cuestiones individuales, legislativas, problemas estatales o cualquier problema que no mejore directamente al IRS ${ }^{19}$; y, (ii) el Low Income Taxpayer Clinics (Programa de clínicas para contribuyentes de bajos ingresos), que ofrece a contribuyentes, de forma gratuita o por una pequeña tarifa, la representación ante el IRS o ante el tribunal de auditorías, apelaciones, asuntos de recaudación de impuestos y otras disputas fiscales, además de brindar educación y divulgación a las personas que hablan inglés como segundo idioma. ${ }^{20}$

Por otra parte, podemos señalar que TAS tiene sus orígenes en el Ombudsman, creado por el IRS en el año 1979, para que se desempeñara como el principal defensor de los contribuyentes. Con el transcurso del tiempo, el Ombudsman fue adquiriendo mayores atribuciones, especialmente a partir del año 1988, con la Declaración de Derechos del Contribuyente $1 .^{21}$

Posteriormente, en el año 1996, se crea la Oficina del Defensor del Contribuyente (TAS), que se mantiene hasta el día de hoy, a través de la Declaración de Derechos del Contribuyente 2. A diferencia del Ombudsman, TAS tiene mayores atribuciones e independencia para prestar ayuda a los contribuyentes, encontrándose especialmente facultado para $^{22}$ :

(i) Identificar las áreas en las que los contribuyentes tienen problemas en las relaciones con el IRS y proponer cambios en las prácticas administrativas del IRS para mitigar o resolver los problemas identificados;

(ii) Informar al Congreso sobre problemas y dificultades recurrentes y no resueltas, que los contribuyentes debían enfrentar al tratar con el IRS;

(iii) Reportar al Congreso mediante dos informes anuales, emitidos de forma directa e independiente por el Defensor Nacional del Contribuyente, y en los que se contengan los objetivos para el próximo año fiscal, iniciativas para mejorar los servicios al contribuyente y capacidad de respuesta del IRS, y un resumen de los problemas más graves que enfrentan los contribuyentes;

(iv) Establecer fechas límite de actuación para el IRS;

(v) Defensa de contribuyentes caso por caso, especialmente en: reembolsos no recibidos, falta de respuesta a solicitudes o preguntas, problemas de notificación,

19 [Taxpayer Advocacy Panel]. (s.f.), https://www.improveirs.org

20 [Low Income Taxpayer Clinics]. (s.f.), https://taxpayeradvocate.irs.gov/about/litc

21 [Taxpayer Advocate Service]. (s.f.), https://taxpayeradvocate.irs.gov/about/our-history

22 [U.S. Code $§ 7803$. Commissioner of Internal Revenue; other officials. National Taxpayer Advocate; (ii) Functions of office]. (s.f.), https://www.law.cornell.edu/uscode/text/26/7803 
casos de urgencia que deben ser atendidos rápidamente en favor de los contribuyentes, como en el caso de embargos; demora de más de 30 días en resolver problemas de la cuenta del contribuyente; $y$,

(vi) Actuar con discreción, para no revelar al IRS el hecho de que el contribuyente se comunicó con la Oficina del Defensor del Contribuyente o cualquier información proporcionada por el contribuyente.

\subsection{México}

En México, la defensa del contribuyente se encuentra a cargo de la Procuraduría de la Defensa del Contribuyente (PRODECON), organismo público descentralizado, no sectorizado, con personalidad jurídica y patrimonio propios, con autonomía técnica, funcional y de gestión, especializado en materia tributaria ${ }^{23}{ }^{24}$, que surgió mediante decreto legislativo de fecha 4 de septiembre de 2006, pero que recién con fecha 1 de septiembre de 2011 abrió sus puertas al público y entró en funciones.

La PRODECON otorga servicios a través del Procurador de la Defensa del Contribuyente, Delegados Regionales y asesores jurídicos ${ }^{25}$ El Procurador de la Defensa del Contribuyente es designado por el Senado de la República o, en su caso, por la Comisión Permanente del Congreso de la Unión, de entre la terna que someta a su consideración el Presidente de la República. Tiene duración de cuatro años en su cargo, pudiendo ser ratificado en un segundo período. Durante el ejercicio de su cargo, se le prohíbe al Procurador desempeñar ningún otro cargo público, de elección popular, empleo o comisión, salvo actividades académicas. ${ }^{26}$

Por otra parte, la PRODECON cuenta con otro organismo denominado "Órgano de Gobierno de la Procuraduría" ${ }^{27}$, que es un cuerpo colegiado integrado por el Procurador de la Defensa del Contribuyente y seis consejeros independientes, designados por el titular del Ejecutivo. ${ }^{28}$ La importancia del Órgano de Gobierno radica en que es el organismo que analiza y aprueba el presupuesto de PRODECON y aprueba el nombramiento de los

23 Artículo 2 inciso I de la Ley Orgánica de la Procuraduría de la Defensa del Contribuyente.

24 [Procuraduría de la Defensa del Contribuyente, México]. (s.f.), http://www.prodecon.gob.mx/ index.php/home/que-es-prodecon

25 Ley Orgánica de la Procuraduría de la Defensa del Contribuyente, Arts. 4 y 6.

26 Ley Orgánica de la Procuraduría de la Defensa del Contribuyente, Art. 9 .

27 Ley Orgánica de la Procuraduría de la Defensa del Contribuyente, Art. I2.

28 Su importancia en este organismo radica en contar con el voto de calidad en caso de empate en las decisiones del órgano de gobierno. 
delegados estatales regionales de la Procuraduría ${ }^{29}$, ratificando de este modo la independencia incluso económica de PRODECON.

En este sentido, el presupuesto para actuar es determinado por la propia Procuraduría, con sujeción a la Ley Federal de Presupuesto, y luego se envía a la Secretaría de Hacienda y Crédito Público para su incorporación, sin que éste pueda ser menor al asignado en el ejercicio inmediato anterior. ${ }^{30}$

Respecto a las facultades de PRODECON, podemos señalar que se encarga de la protección de los derechos y garantías de los contribuyentes mediante las siguientes atribuciones ${ }^{31}{ }^{32}$ :

(i) Orientación a los contribuyentes;

(ii) Asesoría a los contribuyentes, incluso por correo electrónico ${ }^{33}$;

(iii) Representación legal y defensa ${ }^{34}$, patrocinando al contribuyente ante las autoridades fiscales y jurisdiccionales, a nivel federal para la interposición de los medios de defensa y acciones legales que procedan;

(iv) Se encuentra facultado para conocer e investigar de quejas de los contribuyentes afectados por actos de autoridades fiscales federales por presuntas violaciones a sus derechos, y formular recomendaciones públicas no vinculatorias, respecto a la legalidad de los actos de dichas autoridades ${ }^{35}$;

(v) Puede ejercer acciones de investigación que tengan por objeto conocer, esclarecer o acreditar los hechos motivo de la queja o reclamación, a petición de parte o de oficio. Pueden comprender la inspección, observación, solicitud de información o documentación, mesas de trabajo, entrevista o cualquier otra acción análoga ${ }^{36}$;

29 Ley Orgánica de la Procuraduría de la Defensa del Contribuyente, Art. I3.

30 Ley Orgánica de la Procuraduría de la Defensa del Contribuyente, Art. 2 inc. 2 y 3.

31 Ley Orgánica de la Procuraduría de la Defensa del Contribuyente, Art. 5.

32 Lineamientos que regulan el ejercicio de las atribuciones sustantivas de la Procuraduría de la Defensa del Contribuyente, Art. 5 .

33 Lineamientos que regulan el ejercicio de las atribuciones sustantivas de la Procuraduría de la Defensa del Contribuyente, Art. 23.

34 Cabe señalar que para que proceda esta facultad, el sueldo del contribuyente beneficiario no debe exceder de 30 veces el salario mínimo vigente en el Distrito Federal elevado al año y, además, no debe contar con un abogado particular que lo represente y defienda respecto del asunto en concreto.

Lineamientos que regulan el ejercicio de las atribuciones sustantivas de la Procuraduría de la Defensa del Contribuyente, Art. 37 .

36 Lineamientos que regulan el ejercicio de las atribuciones sustantivas de la Procuraduría de la Defensa del Contribuyente, Art. 47. 
(vi) Puede proponer al Servicio de Administración Tributaria (SAT) modificaciones a su normativa interna o estrategias, con el propósito de identificar disposiciones que afecten los derechos y seguridad jurídica de los contribuyentes ${ }^{37}$;

(vii) Puede investigar y analizar los problemas sistémicos de los contribuyentes, con el objeto de proponer a la autoridad fiscal federal correspondiente las medidas correctivas, sugerencias o las recomendaciones que procedan para salvaguardar los derechos de los contribuyentes. ${ }^{38}$ Para estos efectos, puede reunirse con autoridades fiscales, grupos organizados de contribuyentes, colegios $\mathrm{y}$ asociaciones profesionales ${ }^{39}$;

(viii) Puede emitir opiniones técnicas, a petición del SAT ${ }^{20}$;

(ix) Puede reunirse con autoridades fiscales federales, con el objeto de mejorar y fortalecer las relaciones entre autoridades y contribuyentes ${ }^{41}$;

(x) Puede presentar propuestas ante la Comisión de Hacienda y Crédito Público de la Cámara de Diputados, sobre modificaciones a las disposiciones fiscales ${ }^{42}$;

(xi) Puede asesorar en acuerdos conclusivos, como medio alternativo para resolver de forma anticipada y consensuada los diferendos y desavenencias que durante el ejercicio de facultades de comprobación surjan entre contribuyentes y autoridades fiscales ${ }^{23} ; \mathrm{y}$,

(xii) Puede promover y difundir una nueva cultura contributiva realizando campañas de comunicación y difusión social respecto de los derechos y garantías de los contribuyentes, proponiendo mecanismos que alienten a éstos a cumplir voluntariamente con sus obligaciones tributarias, de las atribuciones y límites de las autoridades fiscales federales. ${ }^{44}$

37 Lineamientos que regulan el ejercicio de las atribuciones sustantivas de la Procuraduría de la Defensa del Contribuyente, Art. $5^{8}$.

38 Lineamientos que regulan el ejercicio de las atribuciones sustantivas de la Procuraduría de la Defensa del Contribuyente, Art. 66.

39 Lineamientos que regulan el ejercicio de las atribuciones sustantivas de la Procuraduría de la Defensa del Contribuyente, Art. 68.

40 Lineamientos que regulan el ejercicio de las atribuciones sustantivas de la Procuraduría de la Defensa del Contribuyente, Art. 74 y ss.

41 Lineamientos que regulan el ejercicio de las atribuciones sustantivas de la Procuraduría de la Defensa del Contribuyente, Art. 78 y ss.

42 Lineamientos que regulan el ejercicio de las atribuciones sustantivas de la Procuraduría de la Defensa del Contribuyente, Art. $9^{2}$.

43 Lineamientos que regulan el ejercicio de las atribuciones sustantivas de la Procuraduría de la Defensa del Contribuyente, Art. 96 .

44 Ley Orgánica de la Procuraduría de la Defensa del Contribuyente, Art. 5, numeral XV. 


\section{El Defensor del Contribuyente en Chile}

A través del PLMT ${ }^{45}$, se propone la creación de la "Defensoría de Derechos del Contribuyente” (DEDECON), que de acuerdo al Mensaje del Presidente, pretende compatibilizar el rol fiscalizador del SII y los anhelos e inquietudes de los contribuyentes.

Se pretende que DEDECON consista en un servicio público gratuito, descentralizado, dotado de personalidad jurídica y patrimonio propio, que dependa del Ministerio de Hacienda ${ }^{46}$, y que esté a cargo de velar por los derechos de los contribuyentes, especialmente de los más vulnerables, en materias que sean de competencia del SII. ${ }^{27}$

De acuerdo al Proyecto, la Defensoría se encontraría conformada por:

El Defensor Nacional del Contribuyente (el “Defensor”), a quien corresponderá la dirección y administración superior de DEDECON, será nombrado por el Presidente de la República, a través del Sistema de Alta Dirección Pública, y durará cuatro años en su cargo, pudiendo ser renovado por una sola vez en su cargo ${ }^{48}$;

El Subdirector, cargo que será nombrado por el Defensor, se encargará de subrogarlo y cumplir las tareas que éste le delegue ${ }^{49} ; \mathrm{y}$,

Un Consejo de Defensoría del Contribuyente, órgano técnico y colegiado constituido por tres consejeros independientes, que asesorarán y aconsejarán al Defensor en el ejercicio de sus funciones, además de aprobar las resoluciones de carácter general propuestas por el Defensor relacionadas con las políticas, planes y programas de la Defensoría. ${ }^{50}$ Los Consejeros serán nombrados por el Ministerio de Hacienda y durarán dos años en sus cargos. Los Consejeros deben

45 Mensaje $\mathrm{N}^{\circ}{ }^{7}{ }^{\circ}-3^{66}$ del Presidente de la República, de fecha 23 de agosto de 2018.

46 Proyecto de Modernización Tributaria, Artículo 23 que crea la Defensoría del Contribuyente (Art. I).

47 Proyecto de Modernización Tributaria, Artículo 23 que crea la Defensoría del Contribuyente (Art. 3).

48 Proyecto de Modernización Tributaria, Artículo 23 que crea la Defensoría del Contribuyente (Art. 6).

49 Proyecto de Modernización Tributaria, Artículo 23 que crea la Defensoría del Contribuyente (Art. 9 y ss.).

50 Proyecto de Modernización Tributaria, Artículo 23 que crea la Defensoría del Contribuyente (Arts. $\left.5 \mathrm{y} \mathrm{I}_{4}\right)$. 
ser profesionales con reconocida y amplia experiencia académica o laboral en materias de derecho tributario ${ }^{51}$;

Los funcionarios de la Defensoría cesarán en sus cargos por término de sus funciones dispuesto por el Defensor. ${ }^{52}$

Dentro de sus facultades principales, la DEDECON podrá actuar con las siguientes funciones y atribuciones ${ }^{53}$ :

a) Velar por la protección de los derechos de los contribuyentes, por la observancia del principio de legalidad de los actos del SII y, en general, asegurar el respeto del Estado de Derecho por parte de la Administración en materias de tributación fiscal interna;

b) Orientar a los contribuyentes en caso de vulneración de sus derechos y sobre los posibles cursos de acción y medidas para cumplir con los requerimientos del SII. ${ }^{54}$ Podrá conocer de las consultas de los contribuyentes y emitir las opiniones que correspondan ${ }^{55}$;6;

c) Conocer las quejas de los contribuyentes afectados por actos $u$ omisiones del SII que puedan significar una limitación, vulneración o transgresión de sus derechos, y también aquellos que signifiquen una limitación en el ejercicio de actividades económicas ${ }^{57}$;

d) Proponer a las autoridades del SII, las medidas necesarias que deberían ser adoptadas por los funcionarios para la protección de los derechos de los

51 Proyecto de Modernización Tributaria, Artículo 23 que crea la Defensoría del Contribuyente (Art. I6).

52 Proyecto de Modernización Tributaria, Artículo 23 que crea la Defensoría del Contribuyente (Art. 23).

53 Proyecto de Modernización Tributaria, Artículo 23 que crea la Defensoría del Contribuyente (Art. 4).

54 Esta facultad en ningún caso implicaría una prestación de asesorías remuneradas.

55 Cabe destacar que el Proyecto propone cortos plazos de respuesta para los contribuyentes, estableciendo que el funcionario deberá emitir un informe con propuestas de solución en el plazo de cinco días, y una vez notificado el informe, el contribuyente tendrá un plazo de tres días para manifestar su interés en que la Defensoría preste sus servicios.

Proyecto de Modernización Tributaria, Artículo 23 que crea la Defensoría del Contribuyente (Art. 39).

57 Por ejemplo: restricción a la emisión de documentos, presentación de declaraciones de impuesto, rectificaciones $\mathrm{u}$ otras similares. 
contribuyentes; además podrá emitir recomendaciones públicas no vinculantes respecto de actos de la autoridad administrativa que vulneran los derechos del contribuyente o sean contrarios a la ley;

e) Disponer de acciones investigativas para verificar que los actos de la autoridad tributaria se ajusten a derecho; podrá realizar o encomendar la realización de estudios que identifiquen problemas sistémicos que afecten a la generalidad de contribuyentes;

f) Denunciar a las autoridades competentes los hechos de que hubiere tomado conocimiento que puedan dar lugar a responsabilidad penal, civil o administrativa por actos realizados por funcionarios del SII;

g) Actuar como tercero en procedimientos de mediación entre contribuyentes y el SII;

h) Proponer al Ministerio de Hacienda y al Congreso Nacional modificaciones a la normativa tributaria fiscal interna;

i) Proponer modificaciones, o representar la ilegalidad, errores, interpretaciones contrarias a la ley o las que exceden del marco legal a las instrucciones internas, incluyendo circulares, resoluciones y oficios del SII cuando detecte prácticas que vulneren los derechos o la seguridad jurídica de los contribuyentes. También podrá solicitar al SII la emisión de pronunciamientos sobre materias de interés público, en que la normativa legal no sea clara, para que éste señale cuál es la interpretación administrativa vigente ante la existencia de dos o más oficios contradictorios $^{58}$

j) Emitir interpretaciones y opiniones técnicas respecto de la normativa tributaria interna previa solicitud del SII o del Ministerio de Hacienda;

k) Citar y sostener reuniones periódicas con el SII para promover la cooperación entre ambas instituciones, con el objeto de analizar situaciones que afecten los derechos de los contribuyentes, y realizar sugerencias respecto de las actuaciones de la autoridad, advirtiendo o previniendo respecto de ciertos actos, programas o criterios que puedan constituir una vulneración de los derechos de los contribuyentes; y,

1) Promover el estudio, enseñanza y difusión de la normativa tributaria; adoptar todas las medidas de publicidad para informar a los contribuyentes respecto de sus derechos; y fomentar y difundir el cumplimiento tributario.

En este sentido, DEDECON sería una entidad sin facultades jurisdiccionales ni de representación judicial de contribuyentes, pero que podría tener un rol de mediación de conflictos entre el SII y los contribuyentes, evitando posibles litigios costosos y extensos.

58 Las opiniones emitidas por la Defensoría serán admisibles como prueba en procedimientos administrativos y judiciales. 
Tendrá su sede en Santiago y se podrá relacionar con contribuyentes de otras regiones a través de las Intendencias Regionales o Gobernaciones Provinciales. Se pretende que, después de dos años de iniciadas las funciones de DEDECON, el Ministerio de Hacienda emita un informe que analice la necesidad de instalar unidades regionales de DEDECON en otras zonas del país.

\section{Análisis crítico del DEDECON que plantea el PLMT}

\section{a) Naturaleza jurídica}

Conforme con su artículo 1, se trata de un servicio público descentralizado, dotado de personalidad jurídica y patrimonio propio, sometido a la supervigilancia del Presidente, a través del Ministerio de Hacienda. En este punto nos parece fundamental que la DEDECON sea independiente del Poder Ejecutivo y tenga el rango constitucional del Ministerio Público. Se debe recoger la experiencia del Consejo Fiscal Autónomo, que no funcionó cuando era designado directamente por el Poder Ejecutivo.

\section{Objeto}

Conforme con su artículo 3, debe velar por la protección y resguardo de los derechos de los contribuyentes, en especial, los más vulnerables, en materias que sean de competencia del Servicio de Impuestos Internos. Creemos que la DEDECON debe hacer extensivo el resguardo de los derechos de las personas en relación con la actuación del Servicio Nacional de Aduanas, la Tesorería General de la República y las Municipalidades, no se ve ninguna razón jurídica para limitar su competencia.

\section{c) Funciones y atribuciones.}

El artículo 4 enumera en sus letra a) a la t) las 20 actividades que debe realizar la DEDECON, siendo la última de ellas, genérica, "las demás funciones y atribuciones que las leyes le señalen." Su función medular es velar por los derechos constitucionales y legales de los contribuyentes, velar por la observancia del principio de legalidad y, en general, asegurar el respeto del Estado de Derecho. No obstante lo anterior, el defensor no tiene facultades para representar judicialmente a los contribuyentes, lo que es indispensable que se incorpore al proyecto. Hoy el Estado no otorga el privilegio de pobreza para las causas tributarias, por lo cual las personas de escasos recursos económicos no tienen acceso a la justicia.

\section{d) Autoridades}

El artículo 6 del proyecto señala que el Defensor será nombrado por el Presidente de la República por un plazo de cuatro años, renovable por una vez, a través del sistema de Alta 
Dirección Pública. Nos parece que en la designación del Defensor debería participar el Senado. En cuanto al nombramiento de los Consejeros cabe la misma observación anterior.

Los Consejeros, según el inciso 3 del artículo 16, deberán ser profesionales con reconocida y amplia experiencia académica o laboral en materias de derecho tributario. Nos parece que la experiencia académica y laboral debe ser copulativa y no alternativa. El artículo 18 inciso 5, establece que su funcionamiento lo regulará un reglamento dictado por el Ministerio de Hacienda, nos parece que esto no corresponde y debería ser el propio Consejo quien establezca el mismo.

\section{e) Personal}

El artículo 23 establece que el personal de la Defensoría cesará en sus cargos por el término de funciones dispuesto por el Defensor. No estamos de acuerdo con esto, ya que la remoción de los funcionarios debería regirse por el estatuto administrativo. Cabe recordar en este punto que el artículo trigésimo quinto transitorio del proyecto solicita al Congreso autorizar al Presidente a dictar uno o más Decretos con Fuerza de Ley, para regular las plantas del personal, fijar la estructura orgánica de la Defensoría, traspasar funcionarios desde el Servicio de Impuestos Internos y los TTA a la Defensoría, su dotación máxima, su fecha de entrada en vigencia, su regionalización, entre otra serie de materias. Esta modificación ha generado intranquilidad en la asociación de funcionarios de ambas instituciones, y estimamos que debe ser modificada, de tal forma que estas materias sean resueltas por la propia ley, y que el traspaso de funcionarios de una institución a otra sea de carácter voluntario y no una atribución del Ejecutivo.

\section{CONCLUSIONES}

1. En materia tributaria existe una tendencia de parte del Estado a no respetar los derechos de los contribuyentes, por la necesidad de incrementar la recaudación para solventar los crecientes aumentos del gasto público y por detentar en su propia mano la potestad tributaria. Para reparar lo anterior, es indispensable la creación de la Defensoría del Contribuyente, con la debida independencia del Poder Ejecutivo y con facultades para reparar las constantes vulneraciones de derechos a que se ven expuestos los contribuyentes, y que hoy carecen de protección, cuando no cuentan con los recursos para financiar un abogado.

2. Una función esencial de la Defensoría del Contribuyente debe ser la representación administrativa y judicial de los derechos de las personas, dotándola de las facultades necesarias para el ejercicio de los mismos. En la etapa administrativa, debe amparar las quejas de los contribuyentes en contra de la administración tributaria, en el ejercicio de sus facultades discrecionales. En la etapa judicial, debe prestar asesoría legal para litigar ante los tribu-

nales, ya sea para defender el patrimonio de los contribuyentes, en caso que se pretendan aplicar impuestos que no corresponden, o para restablecer el imperio del derecho. 
3. La Defensoría del Contribuyente también cumple una función esencial para mejorar los procedimientos y tiempos de respuesta de parte de la administración tributaria y para identificar las necesidades de los administrados, y proponer los cambios legislativos que se requieran para que el sistema tributario sea más justo.

4. Sin seguridad jurídica no hay Estado de Derecho y, para ello, es indispensable crear el Ombudsman Tributario que resguarde los derechos de los contribuyentes, dándole independencia del Ejecutivo, con presencia regional y con competencia para resolver asuntos de tributaciones internas y externas, de tesorería y municipales.

Cabe hacer notar que mientras este artículo estaba en proceso de producción editorial, el ejecutivo presentó nuevas indicaciones al PMT ( $N^{0} 105-367 /$ de fecha 3 de julio de 2017), dentro de las cuales propone cambios en la configuración del patrimonio de la institución, cambios de redacción que le otorgan un menor control sobre el SII y ponen énfasis en el apoyo a la micro, pequeña y mediana empresa. Además, se ajustan las facultades de la DEDECON en cuanto a que ya no podrá interpretar la norma tributaria, ni proponer a las autoridades del SII las medidas necesarias que deberían ser adoptadas por los funcionarios para la protección de los derechos de los contribuyentes, tampoco propone sino que informa al Ministerio de Hacienda y al Congreso Nacional las modificaciones a la normativa tributaria fiscal interna. Se le faculta para actuar como ministro de fe en las transacciones celebradas entre el SIl y los contribuyentes. Se agrega que constituye un incumplimiento grave de los deberes de los funcionarios de la Defensoría la falta de emisión de actos, decisiones o informes que correspondan y la falta de entrega de información oportuna. Se establece que sus informes y propuestas podrán constituir antecedentes ante un eventual reclamo tributario (antes decía medio de prueba) y sus opiniones son técnicas y no en derecho. Se eliminó la norma que facultaba al Presidente para designar por decreto supremo al primer Defensor. Se establece que los funcionarios de la Defensoría serán nombrados y removidos de acuerdo con las normas del estatuto administrativo. Se elimina la facultad que tenía el Defensor de poner término unilateral a las funciones de los trabajadores. Cuando no se llega a acuerdo con el SII, la Defensoría, en el informe público que emita, ya no podrá identificar al funcionario a quien corresponda adoptar las medidas que reestablezcan los derechos de los contribuyentes. Se establece un plazo de 5 días para que el SII manifieste su opinión sobre la propuesta de modificación de las instrucciones que vulneran los derechos. Se acorta a un año el plazo para que el Presidente organice la institución por decretos supremos y se establece que sólo serán traspasados a la Defensoría, los funcionarios del SII y de los Tribunales Tributarios y Aduaneros que decidan voluntariamente postular y sean seleccionados. Finalmente, se actualiza en la normativa permanente el Intendente y Gobernador por el Delegado Presidencial Regional o Provincial, y en el artículo transitorio se señala que, mientras aquellos no sean nombrados, operarán estos. 


\section{BIBLIOGRAFÍA}

- AEDAF, "Inseguridad Jurídica en España: situación actual y propuesta para el futuro", Paper 13 (diciembre de 2018), http://mediasviewer.wkcols.com/pdfView.ashx?url_data_id=8875526\&repositoryType $=$ es\&action $=$ GET .

- Dalla Corte, Gabriela, "El "Ombudsman”. Expectativas de derechos en el poder con fuerza no vinculante" (Tesis para optar al Título de Doctora en Antropología, de la Universidad de Barcelona, 2000), http://diposit.ub.edu/dspace/bitstream/2445/62405/1/DALLA_ CORTE_OMBUDSMAN.pdf.

- Libertad y Desarrollo, "Propuesta de Modernización Tributaria, efecto en las Pymes" (noviembre de 2018), https://lyd.org/wp-content/uploads/2018/12/encuesta-modernizacion-tributaria-pymes. pdf.

- Rozas, José Andrés y Eva Andrés Aucejo, "El Defensor del Contribuyente un estudio de Derecho Comparado: ITALIA y EEUU. Estudio y Notas" Crónica Tributaria 113 (Facultad de Derecho Financiero y Tributario. Universidad de Barcelona, 2004), https:// www.economistas.es/contenido/REAF/gestor/06-cro-6-113.pdf. 


\section{NORMATIVA CITADA}

Mensaje No 030-366 Santiago, 4 de junio de 2018 y su Ley 21.148 / 2019 publicada el 16 de Febrero, que "crea el Consejo Fiscal Autónomo".

Mensaje N 107-366 Santiago, 23 de agosto de 2018, con el que el Presidente inicia el "Proyecto de Ley que Moderniza la Legislación Tributaria."

Ley Orgánica de la Procuraduría de la Defensa del Contribuyente, México, 07 de septiembre de 2009.

Lineamientos que regulan el ejercicio de las atribuciones sustantivas de la Procuraduría de la Defensa del Contribuyente, México, 27 de mayo de 2014.

\section{JURISPRUDENCIA CITADA}

Sentencia de la Corte Suprema Rechazando Casación, Rol 27.783 del año 2014, de fecha 23 de diciembre del año 2015.

Sentencia de la Corte Suprema de Reemplazo, Rol 32.114 del año 2014, de fecha 14 de septiembre del año 2015.

Sentencia de la Corte de Apelaciones de Santiago, Rol Ingreso Corte Civil 6785 del año 2017, de fecha 26 de octubre del año 2017, considerando noveno.

\section{PÁGINAS WEB}

Taxpayer Advocate Service,

https://taxpayeradvocate.irs.gov/about-tas

International Revenue Service,

https://www.irs.gov/irs-news/ir-01-06.pdf

Taxpayer Advocacy Panel, https://www.improveirs.org

Low Income Taxpayer Clinics,

https://taxpayeradvocate.irs.gov/about/litc

Procuraduría de la Defensa del Contribuyente, https://www.prodecon.gob.mx 